\title{
LA GESTIÓN INFORMÁTICA COMO BASE DE LA GERENCIA EN LA COMPETITIVIDAD ANTE LA RECESIÓN ECONÓMICA POR LA PANDEMIA DEL CORONAVIRUS (COVID-19)
}

\author{
COMPUTER MANAGEMENT AS A BASIS FOR MANAGEMENT IN \\ COMPETITIVENESS IN THE FACE OF THE ECONOMIC RECESSION DUE \\ TO THE CORONAVIRUS PANDEMIC (COVID-19)
}

\author{
Msc.Omaira Mendoza Ferreira*, Msc. Marling Carolina Cordero Diaz** \\ Phd. Ender José Barrientos Monsalve**** \\ *Universidad de Santander-Colombia \\ E-mail: itamendoza@hotmail.com \\ ** Universidad francisco de Paula Santander-Colombia \\ E-mail: marlingcarolinacd@ufps.edu.co \\ Phd. Ender José Barrientos Monsalve \\ ***Universidad tecnológica latinoamericana en línea - México \\ E-mail:dr.ender.utel@gmail.com
}

\begin{abstract}
Resumen: Este documento discute el brote de un nuevo virus el Covid-19, la incertidumbre y la intranquilidad afecto la vida de los seres humanos, la salud, y la economía a nivel mundial; en poco menos de un mes se convirtió en una pandemia que ha afectado a familias y países dejándoles aislados y llevando la economía en declive, cerrando por completo países con la suspensión de vuelos nacionales e internacionales, cancelación de eventos, cerrando establecimientos, colegios, universidades y hasta el cierre de fronteras, en más de 124 países. Afectando directamente e impactando la economía mundial: en la producción, creando trastornos en la cadena de suministro y en el mercado, y por su impacto financiero en las empresas y los mercados financieros, las más afectadas son las pequeñas empresas la pymes, donde resalta la desaceleración y se acerca a una crisis global... la situación de la economía ya así lo refleja, los gobiernos han impuesto medidas drásticas para prevenir la expansión del virus con la cuarentena.
\end{abstract}

Palabras claves: Covid19, pandemia, recesión, crisis, desempleo, emprendimientos, gestión informática.

\begin{abstract}
This document discusses the outbreak of a new Covid-19 virus, the uncertainty and uneasiness affecting human life, health, and the economy worldwide; in little less than a month it became a pandemic that has affected families and countries, leaving them isolated and leading the economy to decline, completely closing countries with the suspension of national and international flights, cancellation of events, closing establishments, schools, universities and until the closing of borders, in more than 124 countries. Directly affecting and impacting the world economy: in production, creating disruptions in the supply chain and in the market, and due to its financial impact on companies and financial markets, the most affected are small companies, SMEs, where the slowdown and approaching a global crisis ... the economic situation already reflects this, governments have imposed drastic measures to prevent the spread of the virus in quarantine.
\end{abstract}

Keywords: Covid19, pandemic, recession, crisis, unemployment, entrepreneurship 


\section{INTRODUCCIÓN}

Es importante describir la problemática que se presenta actualmente en el debate económico actualmente y ya se ha vivido desde siglos pasados por allá en el año (1348 y 1349), que se vivió la peor peste de todos los tiempo que fue la peste negra con la muerte de más de 200millones de personas (Pedroso 2010) con la más grande recesión y depresión de todos los tiempos, ya en el año 1929 el cual duro hasta 1940, donde se vivió una crisis economía parecida a la actual, la discusión economía de esa época tuvo confrontaciones por el diagnóstico y buscar la solución entre los economistas y los keynesianos. Los economistas clásicos siempre defendieron el poder de la mano invisible y la capacidad del sistema económico para retornar el equilibrio, en caso de que se presentaran fuerzas que llevaran al desequilibrio. Lo fundamental sobre absoluta flexibilidad de precios en los mercados de bienes y servicios y de factores de producción, llevaba a los clásicos a la conclusión de que era imposible que el sistema económico pudiera permanecer en desequilibrio por un periodo relativamente prolongado, ya que los precios de los factores, incluyendo los salarios, bajarían o subirían lo suficiente para restablecer el equilibrio del sistema. (Banguero, H 2010).

Por lo tanto, se hacía necesaria la intervención del Estado para reactivar la economía y lograr nuevamente un crecimiento económico sostenido (Keynes, 1936; Sachs y Larrain, 1994). La crisis de 1929, el crac de 1929, también conocido como la gran depresión del 29. En octubre de 1929 la bolsa de New York hace una baja muy muy fuerte, de un $40 \%$, esto que consecuencias trajo, inseguridad económica, miseria, cae la renta nacional es decir que cada persona o familia percibe da un bajón enorme, los ingresos, los beneficios de la empresa y las fábricas, afecta el comercio y sobre todo hay unas tasas de desempleo enorme. (Gracia M. 2009).

Las causas de este crac, recién había pasado la guerra mundial, Europa esta devastada tiene que hacer frente a un montón de pagos de reconstrucción de infraestructuras y no tiene dinero y en ese momento la potencia emergente Estados Unidos es la que apoya económicamente desembolsando un montón de dinero y recursos enviados a Europa para que Europa reflote, a raíz de esto Estados Unidos no deja de enviar y enviar dinero y ahí la gente empieza a ganar mucho dinero por lo que el beneficio es enorme que le están sacando a Europa que hay un momento que todo disminuye y solo hace falta que dos o tres grandes inversores se retiren para que una gran cantidad de pequeños inversores tengan miedo y empiecen a retirar fondos con lo cual la bolsa empieza el desplome, como más baja la bolsa a los inversores le da más miedo y deciden sacar su dinero de la bolsa, por consecuencia la bolsa sigue bajando, entonces América al ver que tiene esta gran crisis lo hace es dejar de ayudar, de exportar productos a Europa, es donde viene el efecto domino, también entra en crisis, es así como se globaliza la gran crisis del 29 la más grande, más larga y la más profunda vivida en la historia del ser humano en la época moderna. (Tassell N 2019)

Lo anterior expuesto genera mucho desempleo, alguno que otro conato de revuelta social y no es sino hasta la elección de Franklin Delano Roosevelt presidente de los estados unidos con sus planes de reactivación económica con el eslogan de New Deal que esto empieza a remontar un poco, como lo consigue generando mucho empleo, haciendo muchas obras públicas para dar trabajo a la gran masa de desempleados, cuando esto desempleados vuelven a tener poder adquisitivo, se establece los especialistas y llegan a la conclusión que se puede dar por terminada la gran crisis de 1929. (Gracia M 2009)

En diciembre de 2019, un coronavirus similar al SARS-CoV, el nuevo coronavirus 2019 (Covid19), surgió en china en la provincia Hubei de huwan y se extendido velozmente en China continental y en otras partes del mundo. (The Lancet 2020). El coronavirus vino arrasar con todo... todos los países del mundo enfrentan emergencia de salud pública, muchas personas empezaron a dar positivo de Covid19, nadie puede salir de sus casas, medida tomada para poder ser contenido el virus, muchas personas asustada por lo síntomas que son muy parecidos un cuadro gripal, declarando en muchos países emergencia sanitaria de interés pública internacional, generando en muchas partes del mundo ansiedad, nerviosismo.

La incertidumbre y la zozobra han aumentado. Siempre se puede echar la vista atrás y analizar qué ha sucedido en situaciones parecidas. Básicamente, tal y como reconoce la OMS en un informe reciente, "las epidemias devastan las economías". Según (Herrera, L 2020) La crisis por el coronavirus arrastra al Ibex 35 a su peor caída 2020) sus estimaciones, en el año 2003 
el SARS provocó pérdidas económicas por valor de más de 40.000 millones de dólares (unos 35.200 millones de euros). La pandemia de Gripe A (H1N1) costó en 2009 entre 45.000 y 55.000 millones de dólares (de 40.000 a 50.000 millones de euros) y entre los años 2014 y 2016 el brote de ébola en África tuvo un impacto de 53.000 millones de dólares (46.600 millones de euros).

Indudablemente esta situación por la crisis de la pandemia obligo a nivel mundial la utilización de la gestión informática o tecnología, cuando en la historia de todas las crisis económicas no se había hecho tan presente esta herramienta ya que casi todas las operaciones o transacciones se llevaban manualmente, claro que hay países que esas tecnologías estaban más avanzados en términos de digitalización o tecnologías estaban más preparados para mitigar de alguna manera los efectos de rutina por la pandemia, obviamente el rango de impacto que implico el SARS en el 2003 comparado con lo que se está viendo ahora (OMG 2003

A partir del inicio de esta pandemia la utilización de las redes de comunicaciones estaba multiplicándose la intensidad con la que las personas están usando la digitalización o las tecnologías con el teletrabajo, el asueto escolar que obligaba a los niños a ir desde sus hogares a seguir llevando su ritmo educativo, la utilización de domicilios hacer compras por internet desde medicinas y alimentos todos estos factores comenzaron a determinar que el tráfico en las redes se estaba incrementado obviamente no se tenían datos en el sentido de probar hasta qué punto la gestión informática, o las herramientas informáticas eran importantes para aliviar de alguna manera todo el sufrimiento que estaba generando esta pandemia. (Universidad de Antioquia 2020)

Ante esta situación se plantea el objetivo de la presente investigación el cual es proponer ideas para ayudar o dar soluciones para recuperar el sistema socio económico sostenible con la ayuda de la gestión del conocimiento y la gestión informática, creando alianzas entre los gobiernos. promoviendo políticas orientadas al desarrollo de nuevas empresas (Pymes), infraestructura de nuevas industrias, empleos de calidad, emprendimientos, innovaciones, inclusión y creatividad. Promover el crecimiento económico sostenible, inclusivo, con empleos plenos y productivos y trabajos decentes para todos. Ya que actualmente es un desafío buscar empleos de calidad para casi todas las economías, además en este paso es fundamental para hacerlas crecer y darle más beneficioso y poder crear más sociedades competitivas. (ONU 2.015)

Sin embargo, es muy importante que se desarrolle e implemente una manera de que la gestión del conocimiento y la gestión informática pueda implementar de una forma de poder ayudar a las empresas a realizar actividades industriales de infraestructura e innovación, para hacer un cambio asía el desarrollo sostenible también en estas áreas dado que es muy importante brindarle a la población trabajos equitativos. La gestión del conocimiento y la gestión informática, han demostrado su importancia; a que se encarga del desarrollo de tecnologías de la información y comunicación, y tiene un enorme efecto en la industrialización $\mathrm{y}$ en la sociedad con la multiplicación de trabajos, esto quiere decir tiene va generar trabajo en otras empresas. (Pérez Y \& Coutín A (2005).

Por lo tanto se plantea el objetivo de la gestión del conocimiento y la gestión informática ayude a generar, proponer y crear ideas para ayudar o dar soluciones para recuperar el sistema socio económico sostenible, creando alianzas entre los gobiernos.

- Conociendo los aspectos más importantes de una recesión.

- Identificar los criterios de qué manera se puede lograr un desarrollo socioeconómico sostenible y sustentable

- Identificar los aspectos más importantes de los sectores financieros fomente el crecimiento industrial e innovación

Examinar los aspectos más importantes a tener en cuenta para la creación de empleos e inclusión (Moreno A, Uribe A \& Serrano J. (2010).

\section{JUSTIFICACIÓN}

La importancia de esta investigación permite observar el nivel en que se puede conseguir el desarrollo socio-económico sostenible, con la industrialización, innovación y tecnologías, creando condiciones necesarias para que las personas puedan tener empleos de calidad con el fin de estimular la economía sin dañar el medio ambiente, y con base a los escenarios actuales de las gestiones informáticas han evolucionado en la economía electrónica como medio de impulso y desarrollo económico, obviamente la (ONU 2015) reconoce que la gestión informática es un gran impulsor importante y que además ayuda a la 
sociedad y al desarrollo económico y al empleo dado que promueve y crea productos y genera ingresos.

Justamente de allí la importancia en la práctica formando profesionales que permitan destacarse en las actividades propias de su ejercicio, teniendo en cuenta que las actividades económicas van cambiando con el tiempo y las estrategias y metodologías debe ir acordes a las herramientas técnicas y tecnológicas que tengamos a nuestro servicio, de allí se crea una evolución en el sistema socio económico, promoviendo el crecimiento, con oportunidades laborales para toda la población en edad de trabajar: mujeres, hombres, jóvenes y personas con discapacidad apoyados en las plataformas digitales informáticas para poder gestionar sus labores eliminando una serie de barreras y aumentando la comunicación en las redes comerciales. (Serradell E, Ángel A \& Pérez J 2003), (Márquez, L, Lara, YA, Ángulo, F 2017)

\section{MÉTODO Y TIPO DE INVESTIGACIÓN.}

La investigación descriptiva de acuerdo con (Sabino C (2000), se define como "un esfuerzo que se emprende para resolver un problema, claro está, un problema de conocimiento" ; tomando en cuenta esta premisa el presente proyecto está enmarcado para buscar la solución de una interrogante, así mismo, el presente estudio es de tipo cualitativo que permitirá recolectar información para su respectivo estudio, así lo refleja (Ñupas et al 2013) señala que este enfoque se utiliza la recolección y análisis de datos, sin preocuparse demasiado de su cuantificación; la observación y la descripción de los fenómenos se realizan pero sin dar mucho énfasis a la medición.

De igual manera, será de carácter descriptiva la cual busca describir situaciones que nos acerquen más a la resolución del objeto de estudio, como lo señala (Salkind (1999:11), “la investigación descriptiva reseña las características de un fenómeno existente", la misma está apoyada en una revisión documental; en este sentido (Alfonso I 1995) refleja que "la investigación documental es un procedimiento científico, un proceso sistemático de indagación, recolección, organización, análisis e interpretación de información o datos en torno a un determinado tema"; por lo tanto, va a proveer de un análisis riguroso de los con el fin de generar unas conclusiones que permitan aclarar la relevancia del objeto de estudio como las diferentes estrategias y actividades para lograr el desarrollo y progreso socio económico del país.

\section{MARCO TEÓRICO}

\section{Que es recesión económica}

Crisis es referencia en una economía de mercado a la cuestión de los ciclos o fluctuaciones económicas, es la disminución general de la actividad económica, reflejada en la baja de la producción de bienes y servicios y del empleo, acompañada por una reducción general del nivel de beneficios, precios y salarios. Según (Rapoport \& Brenta 2010) Una recesión es la caiga económica generalizada, vemos menos personas haciendo compras, saliendo de viaje, una caída en las importaciones o exportaciones si son países vinculados con economías extranjeras y la situación de la recesión económica puede agravarse si viene acompañada de una caída drástica en la valor de los activos financieros como la bolsa de valores o los activos inmobiliarios.

\section{Como afecta la recesión económica a nivel mundial}

La crisis que sacudió al mundo en el inicio del siglo XXI, el banco Lehman Brothers en el año 2008 uno de los bancos más importantes de Estados Unidos estaba en quiebra y además no era el único, obviamente el pánico se extendió en los mercados internacionales, mientras que la economía mundial quedaba al borde del colapso, los más afectados fueron personas o familias; los prestamistas o bancos comerciales los bancos que tradicionalmente conocemos; bancos de inversión entidades que tienen el propósito de conseguir dinero para empresas y para el sector público con la emisión de valores; inversionistas, compañías, gobierno, personas, etc, todos aquellos que llegan al mercado de valores a comprar acciones; las aseguradoras compañías vendedoras de pólizas de seguros contra cualquier riesgo; calificadoras de riesgo compañías que brindan una calificación a las acciones, para que los inversionistas sepan la capacidad de pago de esa acción y por último la participación de la Reserva Federal del banco Central de los Estados Unidos. (Guevara D 2018)

\section{Gestión del conocimiento}

Según (Nofal N 2007) La gestión del conocimiento es un proceso lógico, organizado y sistemático para producir, transferir y aplicar en situaciones concretas una combinación armónica de saberes. Es un conjunto de procesos que dirigen el análisis, diseminación, utilización y traspaso de 
experiencias, información y conocimientos entre los miembros de una organización con el objetivo de crear un ambiente en el que el conocimiento y la información esté disponible en una organización sean accesibles y puedan ser usados para estimularla innovación y hacer una mejor toma de decisiones.

Hay dos formas de visión del conocimiento tácito almacenado en el cerebro individual por tanto es difícil de trasferir y aplicar a los demás, el conocimiento explicito almacenado en documentos (manuales, instrucciones por lo tanto es fácil de transferir y aplicar a los demás. De allí los beneficios de la gestión informática ayuda a ahorrar tiempo, evita el trabajo doble, mejora los flujos de conocimiento interno, aumenta el grado de compromiso, mejora la localización de conocimientos existentes, identifica conocimientos críticos, evita perdidas de conocimiento. (Pereira $\mathrm{H}$ 2011)

\section{Gestión informática o tecnología}

Los procesos de globalización, el desarrollo de las nuevas tecnologías de información y comunicación (TIC) y su implementación para agilizar procesos, innovar en servicios y productos, implica cambio de paradigmas no sólo en el funcionamiento de las organizaciones, sino también en el quehacer de los profesionales de la información. (Arellano M. (2008). Con la instalación de software acordes a las instituciones y acordes la demanda, con estos sistemas se pueden evaluar y definir las aplicaciones y sistemas informáticos que resulten más adecuados a la administración y gestión de una organización con la ayuda de un profesional para optimizar el uso de las tecnologías de la comunicación y la información integrando grupos interdisciplinarios seleccionar hardware y software, gestionando sistemas operativos y de seguridad informática que se desarrollan para los organismos, empresas o instituciones. (Agudelo E, Niebles L, \& Gallón L. (2005).

Sabemos que el mundo está cambiando a alta velocidad en el concepto de productividad y la gestión informática llega a reforzar la productividad de las empresas y hacerla más competitivas la dinamizan y ponen más valor agregado a la innovación ayuda a la empresa a la generación de nuevos negocios que es muy importante, cuando tienen claro la gestión informática y como lo aplican empiezan a visualizar el crecimiento real de un empresa (Nava A 2005)

\section{RESULTADOS Y DISCUSIÓN}

Y luego está el factor histórico llámese psicológico y sociológico, estamos indudablemente ante un cambio de era ante un cambio de ciclo y estos cambios marcan a la población que tiene que vivir esos tiempos (Tabla 1), después de una pandemia indudablemente el shock psicológico, sociológico y económico va incitar a la población a volverse más prudente, volverse más precavida y eso va tener efectos en el consumo va ver mayor contracción del gasto va ver mayor prudencia a la hora de gastar y ello indudablemente teniendo en cuenta que el consumo es un pilar importante para la economía va traducirse en un crecimiento económico más lento y en el aspecto sociológico y político también veremos cambios, el fin de Bretton Woods va suponer un disminución muy importante en el individualismo, va dar lugar a una época con un mayor peso de la autoridad y con un mayor peso del estado, lo hemos visto estos días hemos dado más poder al estado para restringir nuestras libertades en aras de un bien mayor que es contener la pandemia y esto es probable que lo sigamos viendo en las próximas décadas, además hay que tener en cuenta que en el sistema en el que vivimos no pasa por un buen momento estamos ante un sistema roto el sistema financiarizado y dominado por la especulación y la falsificación de dinero llega a su fin y es posible un esta pandemia seguida de una crisis económica esa una oportunidad para reformar un sistema roto, una oportunidad que no es seguro que sepamos aprovechar. ¿Creen tu que aprovecharemos esta oportunidad? (Gómez A \& Matinez O 2014).

No todo tiempo histórico es igual hay que tener en cuenta que en esta época se suman otros factores que no se veían en épocas pasadas

\section{Tabla 1 factores históricos de cambios después de una crisis}

\begin{tabular}{|c|c|c|}
\hline \multicolumn{3}{|c|}{$\begin{array}{l}\text { Factores históricos que pueden condicionar una } \\
\text { marcha diferente en la economía después de esta } \\
\text { pandemia }\end{array}$} \\
\hline $\begin{array}{l}\text { Crisis } \\
\text { ecológica }\end{array}$ & $\begin{array}{l}\text { Envejecimiento } \\
\text { de la población }\end{array}$ & $\begin{array}{c}\text { Una } \\
\text { población } \\
\text { mucho más } \\
\text { alta }\end{array}$ \\
\hline $\begin{array}{l}\text { Estamos en } \\
\text { medio de un } \\
\text { severo medio } \\
\text { ambiental, con } \\
\text { independencia } \\
\text { de si creemos o }\end{array}$ & $\begin{array}{l}\text { Factor } \\
\text { demográfico: A } \\
\text { lo largo y ancho } \\
\text { de todo el } \\
\text { mundo ra } \\
\text { población está }\end{array}$ & $\begin{array}{l}\text { también por } \\
\text { supuesto el } \\
\text { número de la } \\
\text { población } \\
\text { actualmente } \\
\text { somos más }\end{array}$ \\
\hline
\end{tabular}




\begin{tabular}{|c|c|c|}
\hline $\begin{array}{l}\text { no en } \\
\text { cambio } \\
\text { climático. } \\
\text { Incluso los } \\
\text { más } \\
\text { negacioncitas } \\
\text { admiten que la } \\
\text { tierra está } \\
\text { próxima a sus } \\
\text { límites } \\
\text { tenemos que } \\
\text { problemas } \\
\text { ecológicos } \\
\text { importantes } \\
\text { hay muchas } \\
\text { especies } \\
\text { están que } \\
\text { exterminadas } \\
\text { que } \\
\text { recursos están } \\
\text { próximos a su } \\
\text { fin lon } \\
\text { Así pues esta } \\
\text { pandemia } \\
\text { esta y } \\
\text { coincide crisis } \\
\text { un periodo de } \\
\text { crisis ecológica }\end{array}$ & 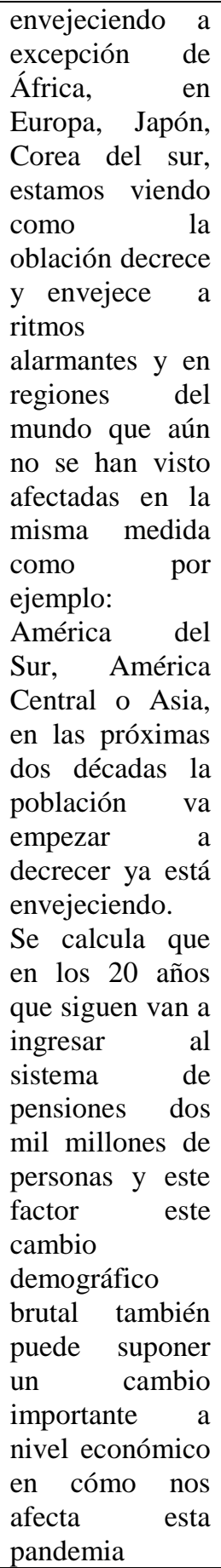 & $\begin{array}{l}\text { de siete mil } \\
\text { millones de } \\
\text { personas en } \\
\text { el mundo, } \\
\text { cuando al } \\
\text { planeta } \\
\text { arribo al } \\
\text { planeta la } \\
\text { gripe mal } \\
\text { llamada } \\
\text { gripe } \\
\text { española en } \\
\text { la segunda } \\
\text { décadas del } \\
\text { siglo 20 la } \\
\text { población } \\
\text { debería estar } \\
\text { entorno a lo } \\
\text { mil millones, } \\
\text { estamos ante } \\
\text { una } \\
\text { población } \\
\text { mundial siete } \\
\text { veces más } \\
\text { alta }\end{array}$ \\
\hline
\end{tabular}

Actualmente las empresas, los países del mundo se van a recuperar de esta crisis como en años pasados ya que la tecnología e información y la manera cómo ha evolucionado y se ha puesto en práctica juega un papel fundamental en la recuperación económica. (Pabón J. 2016)

Muchas empresas no solo las grandes sino también las medianas y pequeñas están enfrentando una difícil situación a partir de la propagación del covid19 que ha enviado a muchos de sus empleados a trabajar desde sus casas, gracias a los avances de la informática y las comunicaciones la tecnología y sus herramientas; ¿Cómo pueden ayudar a todas esas empresas a usurarlas en medio del trabajo remoto?, hay sistemas que se utilizan para compartir documentos, hacer videoconferencias, video llamadas, en esas mismas plataformas se pueden compartir información. Hoy en día gracias a los navegadores existentes pueden ver las tendencias de brindan herramientas en temas de video llamas hay actualizaciones avanzadas, gracias a todas información de tecnologías las empresas solo tienen que buscar la herramienta que más le convenga a dar soluciones y dar respuesta inmediata (Ossa A. (2015)

Las empresas en esto tiempo difíciles e inciertos que no se sabe cuánto tiempo va durar, días, meses a las empresas pymes les ha tocado optar por capacitar y poder dar solución de como comunicase con los cliente; gracias a la actualizaciones de la comunicación ya se pueden de manera virtual hace publicidad, contestar automáticamente las email.

No todas las pymes (Ponce R 2014) tienen o necesitan un gerente de tecnología que tenga las ideas para este tipo de situación, y los gerentes no tienen los conocimientos para poder desarrollar todas la aplicaciones o sistemas necesarios para la toma de decisiones y salir delante ante y afrontar y tomar medidas ante el covid19, en términos de tecnología y de darle continuidad al negocio lo primero es dar acceso a la información, existen driver que es una herramienta usada por miles de usuarios y empresas alrededor del mundo básicamente son carpetas compartidas en la cual puedes tener muchos tipos de información y es un manera de darle acceso segura y fácil a todas las personas de la empresa de la información que necesitan para trabajar desde casa, en este momento y principalmente para las pymes que tiene que tomar decisiones rápidas y que se tiene que adaptarse a. un contexto súper cambiante loa más recomendable y las mas accesible e estos tiempos es adoptar aplicaciones que ya estén listas que no requieran ningún proceso de implementación que prioricen la comunicación, que las personas puedan mantenerse comunicadas como las ya mencionadas por videoconferencias y chats.

Si ya la herramienta informática de conexión y comunicación más utilizada desde ya hace tiempo es el celular, hoy en día se ha vuelto la herramienta 
más usada y más para los empleados que no cuentan con una computadora en sus hogares para los trabaos de oficina ya que ha servido para mantener clientes y proveedores conectados ya se ha vuelto tendencia para las conversaciones de whatsapp ya que no hay límite para poder enviar mensajes de difusión a muchas personas sirve también para trabajar con herramientas de office y aplicaciones para poder realizar publicidad y publicaciones, las pymes y nuevos emprendedores se ha convertido en su mejor aliado par pode compartir en las redes sociales videos en línea lo cuales ya pueden dejar en sus cuentas de redes a todas las personas interesadas en cualquier marca, y lo se ha vuelto una novedad son las los lives donde entrenadores, instructores puedan dar sus cursos.

\section{La gestión empresarial en tiempo de crisis}

La conclusión es clara cuanto más digitalizado este un país, mejor preparado está preparado para afrontar o reducir parcialmente los efectos disruptivos que tiene un pandemia. Mientras más preparado en informática, sistemas digitales, banda ancha y comunicaciones este un país sale mejor a flote en temas de economías. Es la dinámica social que muchos no dominan con respecto a la digitalización y las tecnologías

Latino América, tiene un problema grande desigualdad en muchos aspectos y uno de esos es el acceso a las tecnologías de la información y comunicación, estudios demuestran tal desigualdad, exclusión tecnología y que ha mostrado aún más la vulnerabilidad en muchos segmentos que ya eran vulnerables, en algunos países más del $90 \%$ de los hogares de los más pobres no tienen conexión a internet, otro análisis es por edades los dos grupos con menores conexiones son los niños de 5 a 12 años y los adultos mayores de 55 años, esto es un muestra de 11 países, son 36 millones de niños que no están conectados y 18 millones de adultos mayores, las medidas que se están adoptando como plataforma tienen impacto bastante imitado por esa exclusión digitales. A pesar de todas esa tragedia en medio de la crisis económica.

América latina está hoy mejor preparada que hace dos años en la gestión de la información en cuanto a la infraestructuras de comunicaciones hay factores que nacen desde el interior el ecosistema digital, toda la presión que viene soportando las redes en telecomunicaciones, por ejemplo el incremento del $40 \%$ del tráfico de internet sobre las redes, el $80 \%$ en la subida de datos proveniente de todas las video conferencias referentes al teletrabajo, todo lo que implica a las plataformas de educación, cabe resaltar como América Latina está en capacidad de enfrentar desde lo digital toda la irrupción que esto implica desde los sistema económicos, claramente hay todavía un avance incipiente en lo que es la digitalización de la producción en como todavía hay un largo camino por recorrer en materia adopción y uso de herramientas de comunicación, en cambio estas herramienta en la parte de innovación es un excelente instrumento para la parte logística, mercadeo y marketing digital, y de allí existen plataforma innovadoras oportunidades que se pueden resolver gracias a la utilización de las redes.

\section{REFERENCIAS}

Agudelo E, Niebles L, \& Gallón L. (2005). LA Gestión Tecnológica como Herramienta de Planeación Estratégica y Operativa para las Unidades De Información. Revista Interamericana de Bibliotecología, 28(2), 89-114. Retrieved July 09, 2020, from http://www.scielo.org.co/scielo.php?script $=$ sci_arttext\&pid=S012009762005000200004\&lng=en\&tlng=es

Alfonso I. (1994). Técnicas de investigación bibliográfica. Caracas: Contexto Ediciones. Disponible en: file://C:/Users/usuario/Downloads/Dialne t-InvestigacionUniversitaria-4106976.pdf

Arellano M. (2008). Sistemas de información: ¿adecuación a los cambios tecnológicos o herramienta de gestión?. Revista de Ciencias Sociales, 14(3), 546-560. Recuperado en 11 de julio de 2020, de http://ve.scielo.org/scielo.php?script=sci_a rttext\&pid=S1315$95182008000300008 \& \operatorname{lng}=$ es \&tlng=es.

Banguero, H.(2010) Crisis financiera, recesión económica y globalización El Hombre y la Máquina, núm. 35, julio-diciembre, 2010, pp. 19-26 Universidad Autónoma de Occidente Cali, Colombia. Disponible en: https://www.redalyc.org/articulo.oa?id=47 817140003

Gracia M. (2009). Crisis y salida de la crisis. Espiral (Guadalajara), 16(46), 211217. Recuperado de http://www.scielo.org.mx/scielo.php?scrip $\mathrm{t}=$ sci_arttext\&pid=S1665-

05652009000100008\&lng=es\&tlng=es. 
Gomez A., \& Matinez O. (2014). La Gestión del Conocimiento como Herramienta para la Innovación y el Cambio Incremental en las Organizaciones. Desarrollo Gerencial, 6(2). https://doi.org/10.17081/dege.6.2.471

Guevara D, (2018). El Espectador. Diez años de la crisis de 2008: cuando la economía trabaja para las finanzas. Disponible en: https://www.elespectador.com/economia/d iez-anos-de-la-crisis-de-2008-cuando-laeconomia-trabaja-para-las-finanzasarticulo-738343

Herrera L. (2020). "Noticias sobre Covid-19 y 2019-nCoV en medios de comunicación de España: el papel de los medios digitales en tiempos de confinamiento". El profesional de la información, v. 29, n. 3, e290302. https://doi.org/10.3145/epi.2020.may.02

Márquez, L, Lara, YA, Ángulo, F (2017). Prototipo de control de acceso a aulas y registro automático de asistencia. Revista Tecnologías de Avanzada, ISSN: 16927257

Moreno A, Uribe A \& Serrano J. (2010). La crisis económica mundial. Política y cultura, (34), 281-284. Recuperado en http://www.scielo.org.mx/scielo.php?scrip $\mathrm{t}=$ sci_arttext\&pid=S0188$77422010000200015 \& \operatorname{lng}=\mathrm{es} \&$ tlng=es.

Nava, Á (2005). El impacto de la gestión tecnológica en el contexto empresarial Revista Venezolana de Ciencias Sociales, vol. 9, núm. 2, diciembre, 2005, pp. 488504 Universidad Nacional Experimental Rafael María Baralt Cabimas, Venezuela. Disponible en: https://www.redalyc.org/pdf/309/3099021 4.pdf

Tassell, N (2019) BBC News. Mundo. El crack del 29: como ocurrió la peor crisis en la historia de Wall Street hace 90 años. 26 de octubre de 2019. Disponible en: https://www.bbc.com/mundo/noticias50189619

Nofal N, (2007). La Gestión Del Conocimiento Como Fuente De Innovación. Revista Escuela de Administración de Negocios, (61), 77-87. ISSN: 0120-8160. Disponible en:

https://www.redalyc.org/articulo.oa? $\mathrm{id}=20$ 6/20611495008

Ñaupas, H.; Valdivia, M.; Palacios, J.; Romero, H. (2013). Metodología de la Investigación. Cuantitativa - Cualitativa y Redacción de la Tesis. Bogotá: ediciones de la U. 5ta edición, p. 141

ONU (2015) Objetivos de desarrollo sostenible. Disponible en: https://www.un.org/sustainabledevelopme nt/es/infrastructure/

Organización Mundial de la Salud, (OMS 2003) El brote de SRAS ha sido contenido en todo el mundo. Centro de prensa 2003. Dipoonible en: https://www.who.int/mediacentre/news/rel eases/2003/pr56/es/

Pabón J. 2016 Gestión del conocimiento y políticas de innovación. Revista La Propiedad Inmaterial n. ${ }^{\circ}$ 22, Universidad Externado de Colombia, julio-diciembre 2016, pp. 19-31.

doi: http://dx.doi.org/10.18601/16571959. n22.02.

Pereira H. (2011) Implementación de la Gestión del Conocimiento en la empresa No. 135, 2011 Centro de Gestión de Conocimiento, CEGESTI

https://www.cegesti.org/exitoempresarial/ publicaciones/publicacion_135_310111_e s.pdf

Pérez Y \& Coutín A (2005). La gestión del conocimiento: un nuevo enfoque en la gestión empresarial. ACIMED, 13(6) Recuperado en http://scielo.sld.cu/scielo.php?script=sci_a rttext\&pid=S102494352005000600004\&lng=es\&tlng=es.

Rapoport, \& Brenta, (2010). La crisis económica mundial: ¿El desenlace de cuarenta años de inestabilidad? Problemas del desarrollo, 41(163), 7-30. Recuperado en http://www.scielo.org.mx/scielo.php?scrip $\mathrm{t}=\mathrm{sci}$ arttext\&pid=S0301$70362010000400002 \& \operatorname{lng}=\mathrm{es} \& \operatorname{tlng}=\mathrm{es}$

Pedroso P. (2010). La peste, enfermedad infectocontagiosa reemergente. Revista Cubana de Medicina General Integral, 26(2) Recuperado en http://scielo.sld.cu/scielo.php?script=sci_a rttext\&pid=S0864-

$21252010000200016 \& \operatorname{lng}=\mathrm{es} \& \ln \mathrm{ln}=\mathrm{es}$

Ponce R. (2014) Revista Opinión Empresas en crisis: ¿Qué Hacer? Disponilble en https://www.estrategiaynegocios.net/opini on/709169-345/empresas-en-crisisqu\%C3\%A9-hacer

Sabino C. (2000). El Proceso de Investigación. Panamericana, Bogotá, y Ed. Lumen, Buenos Aires. 1992, 216 págs. Disponible en 
http://paginas.ufm.edu/sabino/ingles/book/ proceso investigacion.pdf

Salkind, N. (1999). Métodos e investigación. (3era Ed.). Prentice Hall. México, México https://bit.ly/3eX3yhm

Serradell E, Ángel A \& Pérez J 2003. La gestión del conocimiento en la nueva economía. Universitat Oberta de Catalunya. Disponible en: https://www.uoc.edu/portal/es/

The Lancet 2020 Respiratory Medicine. Hallazgos patológicos de COVID-19 asociados con el síndrome de dificultad respiratoria aguda. VOLUMEN 8, NÚMERO 4, P420422,01 DE ABRIL DE 2020 https://bit.ly/2Zhe1PA

Universidad de Antioquia Teletrabajo, prioridad más allá de la pandemia 07/04/2020 https://bit.ly/3fhzJZq 